\title{
Bioinorganic Chemistry in Thyroid Gland: Effect of Antithyroid Drugs on Peroxidase-Catalyzed Oxidation and lodination Reactions
}

\author{
Gouriprasanna Roy and G. Mugesh \\ Department of Inorganic and Physical Chemistry, Indian Institute of Science, Bangalore 560 012, India
}

Received 19 June 2006; Accepted 29 August 2006

Propylthiouracil (PTU) and methimazole (MMI) are the most commonly used antithyroid drugs. The available data suggest that these drugs may block the thyroid hormone synthesis by inhibiting the thyroid peroxidase (TPO) or diverting oxidized iodides away from thyroglobulin. It is also known that PTU inhibits the selenocysteine-containing enzyme ID-1 by reacting with the selenenyl iodide intermediate (E-SeI). In view of the current interest in antithyroid drugs, we have recently carried out biomimetic studies to understand the mechanism by which the antithyroid drugs inhibit the thyroid hormone synthesis and found that the replacement of sulfur with selenium in MMI leads to an interesting compound that may reversibly block the thyroid hormone synthesis. Our recent results on the inhibition of lactoperoxidase (LPO)-catalyzed oxidation and iodination reactions by antithyroid drugs are described.

Copyright ( $) 2006$ G. Roy and G. Mugesh. This is an open access article distributed under the Creative Commons Attribution License, which permits unrestricted use, distribution, and reproduction in any medium, provided the original work is properly cited.

\section{INTRODUCTION}

Thyroxine or $3,3^{\prime}, 5,5^{\prime}$-tetraiodothyronine (T4) is the major hormone secreted by the follicular cells of the thyroid gland. This hormone is produced on thyroglobulin by thyroid peroxidase (TPO)/hydrogen peroxide/iodide system. The synthesis of T4 by TPO involves two independent steps: iodination of tyrosine and phenolic coupling of the resulting iodotyrosine residues $[1-5]$. The prohormone T4 is then converted to its biologically active form $\mathrm{T} 3$ by an outer ring deiodination pathway. This particular reaction is catalyzed by a selenocysteine-containing enzyme called iodothyronine deiodinase (ID-I), which is present in highest amounts in liver, kidney, thyroid, and pituitary [6-16]. The thyroid gland also produces an inactive metabolite $\mathrm{rT} 3$ by an inner ring deiodination pathway. The triiodo derivatives T3 and rT3 are further metabolized by inner ring and outer ring deiodination, respectively, by ID-I, ID-II, and ID-III to produce the inactive metaboilite T2 $\left(3,3^{\prime}-\mathrm{T} 2,3,5-\mathrm{T} 2\right.$, and $\left.3^{\prime}, 5^{\prime}-\mathrm{T} 2\right)$. The outer ring $5^{\prime}$-deiodination catalyzed by the ID-I enzyme is considered to be the first step in thyroid hormone action because this is the only deiodination pathway that leads to the formation of an active thyroid hormone. It is now widely accepted that the deiodination catalyzed by ID-I is a ping-pong, bisubstrate reaction in which the selenol (or selenolate) group of the enzyme (E-SeH or $\left.\mathrm{E}^{-} \mathrm{Se}^{-}\right)$first reacts with thyroxine (T4) to form a selenenyl iodide (E-SeI) intermediate. Subsequent reaction of the selenenyl iodide intermediate with an as yet unidentified intracellular cofactor completes the catalytic cycle and regenerates the enzyme active site (Figure 1) $[8,14]$. Although it is customary to use dithiothreitol (DTT, 1,4-dithiothreitol, Cleland's reagent) as the second substrate in in vitro experiments, the identity of the physiological second substrate is still uncertain. The tripeptide glutathione (GSH) can also act as a thiol cosubstrate, but GSH is a much less potent cofactor than DTT for ID-I $[10,17]$. In addition to GSH, other native thiols such as dihydrolipoic acid or dihydrolipoamide may serve as cofactors for ID-I $[17,18]$. Therefore, Figure 1 may be an incomplete or incorrect representation of the catalytic mechanism of ID-I since evidence for the cofactor systems mentioned above has only been presented for in vitro studies and not for in vivo analysis.

Although the deiodination reactions are essential for the function of thyroid gland, the activation of thyroid stimulating hormone (TSH) receptor by autoantibodies leads to an overproduction of thyroid hormones. As these antibodies are not under pituitary feedback control system, there is no negative influence on the thyroid activity and, therefore, the uncontrolled production of thyroid hormones leads 


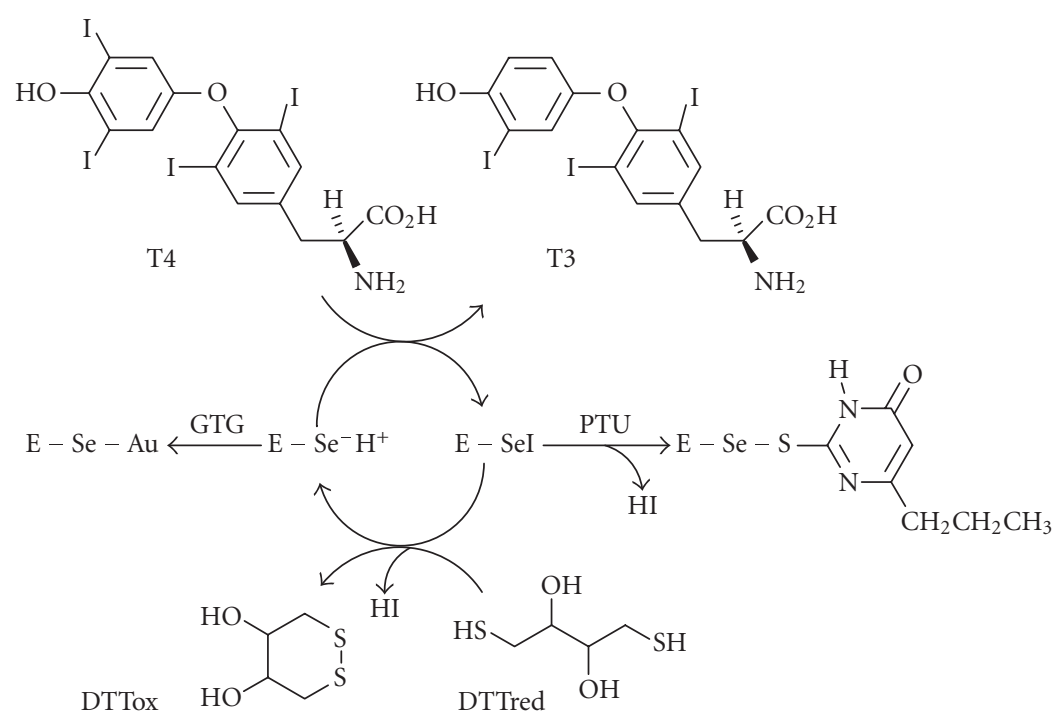

FIgURE 1: Proposed mechanism for the deiodination of thyroxine by ID-I and inhibition of ID-I by $n$-propyl-2-thiouracil (PTU) and gold thioglucose (GTG).<smiles></smiles>

(1), $\mathrm{E}=\mathrm{S}(\mathrm{MMI})$

(2), $\mathrm{E}=\mathrm{Se}(\mathrm{MSeI})$<smiles></smiles>

(5), $\mathrm{E}=\mathrm{S}(\mathrm{MTU})$

(6), $\mathrm{E}=\mathrm{Se}(\mathrm{MSeU})$

FIGURE 2: Chemical structures of some commonly employed antithyroid drugs and their selenium analogues.

to a condition called "hyperthyroidism." The overproduction of T4 and T3 can be controlled by blocking the thyroid hormone biosynthesis or reducing the conversion of T4 to T3. The thiourea drugs such as methimazole (1, MMI), 6-npropyl-2-thiouracil (3, PTU), and 6-methyl-2-thiouracil (5, MTU) are generally employed for this purpose (Figure 2). Despite the importance of these antithyroid drugs in the treatment of hyperthyroidism, the detailed mechanism of their action is still not clear. According to the initially proposed mechanism, these drugs may divert oxidized iodides away from thyroglobulin by forming stable electron donoracceptor complexes with diiodine, which can effectively reduce the thyroid hormone biosynthesis $[19,20]$. It has also been proposed that these drugs may block the thyroid hormone synthesis by coordinating to the metal center of thyroid peroxidase (TPO) [21]. After the discovery that the ID-I is responsible for the activation of thyroxine, it has been reported that PTU, but not MMI, reacts with the selenenyl iodide intermediate (E-SeI) of ID-I to form a selenenyl sulfide as a dead end product, thereby blocking the conversion of T4 to T3 during the monodeiodination reaction (Figure 1) $[8,14,22-24]$. The mechanism of antithyroid activity is further complicated by the fact that the gold-containing drugs such as gold thioglucose (GTG) inhibits the deiodinases by reacting with the selenol (or selenolate) group of the native enzyme (Figure 1) $[8,24]$.

In recent years, the selenium analogues 2 (MSeI), 4 (PSeU), and $6(\mathrm{MSeU})$ attracted considerable attention because these compounds are expected to be more nucleophilic than their sulfur analogues and the formation of an $-\mathrm{Se}-\mathrm{Se}-$ bond may occur more readily than the formation of an -Se-S- bond with the ID-I enzyme [25-29]. However, the data derived from the inhibition of TPO by selenium compounds show that these compounds may inhibit the TPO activity by a different mechanism. We have recently shown that the unexpected behavior of the selenium compound MSeI as compared to that of its sulfur analogue may be due to the existence of this compound in the zwitterionic form and its facile oxidation to the corresponding diselenide (8) $[30,31]$. In this paper, we summarize our recent results on the effect of antithyroid drugs on peroxide-catalyzed oxidation and iodination reactions. In addition, we show that the replacement of sulfur with selenium in MMI leads to an interesting compound (MSeI) that exhibits significant glutathione peroxidase (GPx)-like antioxidant activity.

\section{INHIBITION OF LACTOPEROXIDASE-CATALYZED OXIDATION BY ANTITHYROID DRUGS}

The effect of antithyroid drugs on peroxidase-catalyzed oxidation was studied in vitro by using spectroscopic 
TABLE 1: Inhibition of LPO activity by $1-3$, and 5 [31].

\begin{tabular}{l|cr}
\hline No & Compound & $\mathrm{IC}_{50}(\mu \mathrm{M})^{\mathrm{a}}$ \\
\hline 1 & MMI (1) & $7.0 \pm 1.1$ \\
2 & MSeI (2) & $16.4 \pm 1.5$ \\
3 & PTU (3) & $45.0 \pm 2.1$ \\
4 & MTU (5) & $47.8 \pm 0.1$ \\
\hline
\end{tabular}

${ }^{\text {a }}$ Concentration of the compound causing 50\% inhibition. Each $\mathrm{IC}_{50}$ value was calculated from at least three independent experiments.

techniques. The enzyme inhibition experiments were carried out with iron-containing lactoperoxidase (LPO) since it is readily available in purified form. Furthermore, LPO has been shown to behave very similarly to TPO with respect to oxidation of organic substrates and iodination of thyroglobulin and other iodide acceptors [32]. We have employed 2,2'azio-bis-3-ethyl-benthiazoline-6-sulfonic acid (ABTS) and $\mathrm{H}_{2} \mathrm{O}_{2}$ as substrates [33] to determine the half-maximal inhibitory concentration $\left(\mathrm{IC}_{50}\right)$ of test compounds. The $\mathrm{IC}_{50}$ values for the inhibition of LPO-catalyzed oxidation of ABTS by $1-3$ and 5 are summarized in Table 1 [31]. The sulfur compound MMI inhibited the LPO activity with an $\mathrm{IC}_{50}$ value of $7.0 \pm 1.1 \mu \mathrm{M}$, which is much lower than those observed with PTU and MTU. The selenium analogue (2) also inhibited LPO activity and the $\mathrm{IC}_{50}$ value was found to be almost 2-3 times lower than those of PTU and MTU. The higher activity of MMI as compared with those of PTU and MTU is in agreement with the previous studies on the inhibition of TPO. Since the activation of the iron center in TPO must proceed through an interaction of $\mathrm{Fe}(\mathrm{III})$ with $\mathrm{H}_{2} \mathrm{O}_{2}$, TPO inactivation may occur through a competitive coordination of the drug to iron, assisted by hydrogen bonding with a histidine residue of the TPO enzyme [34]. Under these conditions, MMI might compete more successfully than PTU with $\mathrm{H}_{2} \mathrm{O}_{2}$ because the hydrogen-bond (hard) basicity $\mathrm{p} k_{\mathrm{HB}}$ value of MMI (2.11) is much higher than that of PTU ( 1.32). Similarly to PTU, the methyl derivative 5 is also expected to be a weak inhibitor of TPO. On the other hand, compound 2, which exists predominantly in the zwitterionic form (Scheme 1) [35], probably does not have the ability to coordinate to the iron center; therefore, this compound may inhibit the LPO activity by a different mechanism. Although the zwitterionic selenolate can be oxidized in solution to give the corresponding diselenide (8), the observed inhibitory activity must be ascribed entirely to the presence of the reduced form (2) as the oxidized compound (8) does not show any noticeable inhibition behavior under identical experimental conditions.

Taurog et al have shown that MMI and related derivatives irreversibly inhibit LPO and TPO, leading to a complete inactivation of the enzymes [36-39]. Doerge and others have shown that mammalian peroxidases including LPO may activate the antithyroid drugs through S-oxygenation to produce the corresponding sulfoxides or sulfinic acids [40, 41]. They have also shown that the suicide inactivation of LPO and TPO by MMI proceeds through the S-oxygenation of the thione moiety to form a reactive sulfinic acid, which binds

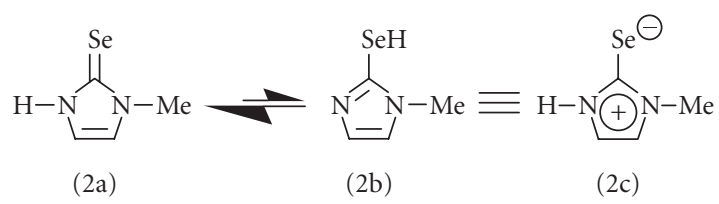

Scheme 1: The possible tautomeric structures of compound 2. The compound exists predominantly in its zwitterionic form $2 \mathrm{c}$, which may have a partial C-Se double bond character.

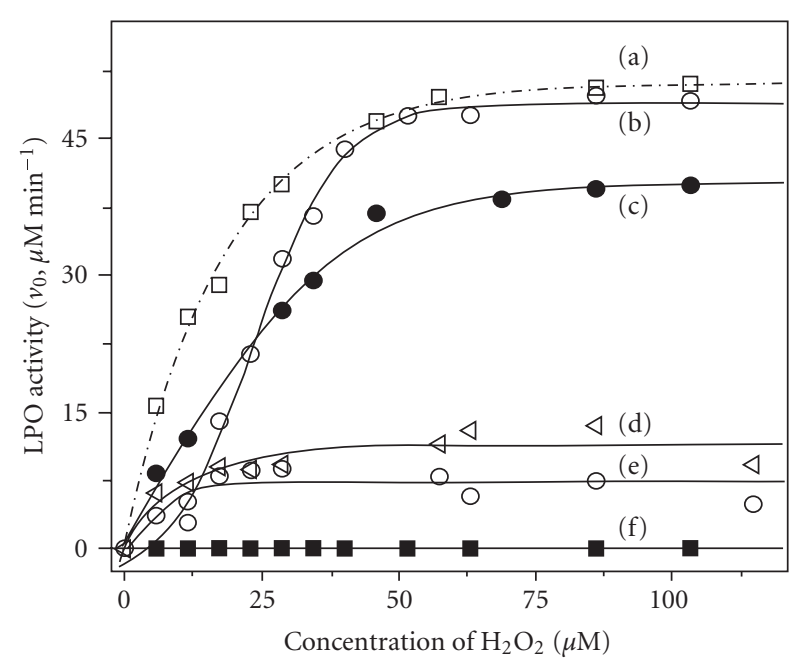

FIGURE 3: Plot of initial rates $\left(\mathrm{v}_{o}\right)$ for the LPO-catalyzed oxidation of ABTS versus concentration of $\mathrm{H}_{2} \mathrm{O}_{2}$ : (a) control activity; (b) $40 \mu \mathrm{M}$ of 2 ; (c) $40 \mu \mathrm{M}$ of 8 ; (d) $80 \mu \mathrm{M}$ of PTU; (e) $80 \mu \mathrm{M}$ of MTU; (f) $40 \mu \mathrm{M}$ of MMI. Conditions: LPO: $6.5 \mathrm{nM} ; \mathrm{H}_{2} \mathrm{O}_{2}: 22.9 \mu \mathrm{M}$ (see [31]).

covalently to the prosthetic heme and irreversibly blocks enzyme activity [42-45]. Given the higher reactivity of selenium compounds as compared with the sulfur derivatives toward oxidation, it is possible that the facile oxidation of the selenium compounds may lead to an efficient inhibition of LPO activity. With this in mind, we treated MMI, PTU, MTU, and MSeI with $\mathrm{H}_{2} \mathrm{O}_{2}$ before adding LPO and ABTS. The LPO activity was measured several times by increasing the time for the reaction of the test compounds with $\mathrm{H}_{2} \mathrm{O}_{2}$. Remarkably, MSeI (2) inhibited the enzyme within few seconds even at lower concentrations, which can be ascribed to the facile oxidation of the reactive selenolate group in 2 (MSeI) by $\mathrm{H}_{2} \mathrm{O}_{2}$ or by the oxidized enzyme. Because MMI also inhibits the enzyme very efficiently, we have carried out further experiments to prove that the mechanisms by which MMI and MSeI exert their inhibitory action are different. The initial rates $\left(\mathrm{v}_{0}\right)$ derived from various concentrations of $\mathrm{H}_{2} \mathrm{O}_{2}$ were plotted against the concentration of $\mathrm{H}_{2} \mathrm{O}_{2}$. The LPO activity was completely inhibited by $40 \mu \mathrm{M}$ MMI, and the enzyme's activity could not be recovered by increasing the $\mathrm{H}_{2} \mathrm{O}_{2}$ concentration (Figure 3f) [31]. The LPO activity could not be recovered even at lower concentration of MMI $(10 \mu \mathrm{M})$ and higher concentration of $\mathrm{H}_{2} \mathrm{O}_{2}(230 \mu \mathrm{M})$. This 


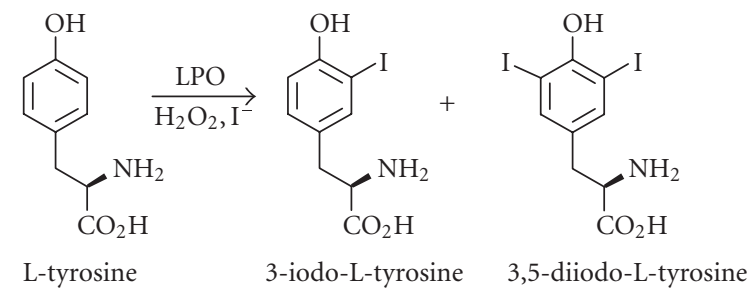

SCHeme 2: Iodination of L-tyrosine by LPO/peroxide/iodide system.

suggests that MMI does not act on $\mathrm{H}_{2} \mathrm{O}_{2}$ but acts on the enzyme itself, leading to an irreversible inhibition as previously proposed. On the other hand, 2 also inhibited the LPO activity as efficiently as MMI, but in this case, the enzyme's activity could be completely recovered by increasing $\mathrm{H}_{2} \mathrm{O}_{2}$ concentration (Figure $3 b$ ). These observations may support the assumption that MSeI, in contrast to MMI, does not interfere with the native enzyme directly but it inhibits the LPO activity by reducing the $\mathrm{H}_{2} \mathrm{O}_{2}$, which is required for the oxidation of the iron center in LPO. The reduction of $\mathrm{H}_{2} \mathrm{O}_{2}$ by 2 may become more efficient in the presence of suitable thiols such as GSH because this process may constitute a redox cycle involving a catalytic reduction of $\mathrm{H}_{2} \mathrm{O}_{2}$ (glutathione peroxidase (GPx) activity) [46]. Thus, compound 2 mimics the action of GPx, a selenoenzyme that protects the cellular components from oxidative damage by reducing $\mathrm{H}_{2} \mathrm{O}_{2}$ with the help of GSH [16]. Recently, the GPx enzyme present in thyroid gland has been shown to inhibit the iodination reactions by degrading the intracellular $\mathrm{H}_{2} \mathrm{O}_{2}[47,48]$. The high GPx activity of the key compound 2 leads to an assumption that the antithyroid drugs may act as antioxidants in addition to their inhibition behavior.

\section{INHIBITION OF LACTOPEROXIDASE-CATALYZED IODINATION BY ANTITHYROID DRUGS}

The interesting results that we obtained from the inhibition of LPO-catalyzed oxidation reactions by MSeI (2) prompted us to study the effect of this compound and related derivatives on the LPO-catalyzed iodination reactions [49]. In addition, we have studied the reactivity of MSeI toward iodine because the effect of the selenium compounds on the iodination of tyrosine and the identification of the products formed in the reactions of these compounds with iodine are crucial in understanding the mechanism of action in vivo of these drugs. The iodination of tyrosine was studied by using $\mathrm{LPO} / \mathrm{H}_{2} \mathrm{O}_{2} / \mathrm{I}^{-}$assay and the initial rates for the conversion of L-tyrosine to 3-iodo L-tyrosine (Scheme 2) were determined by an HPLC method.

As the formation of 3,5-diiodo-L-tyrosine was also observed in the reaction, only the initial $5 \%-10 \%$ of the conversion was followed where only a trace amount of the diiodo compound was produced. The decrease in the concentration of L-tyrosine was followed by measuring the peak area at $277 \mathrm{~nm}$ and the amount of tyrosine present in the solution at a given time was calculated from the calibration plot

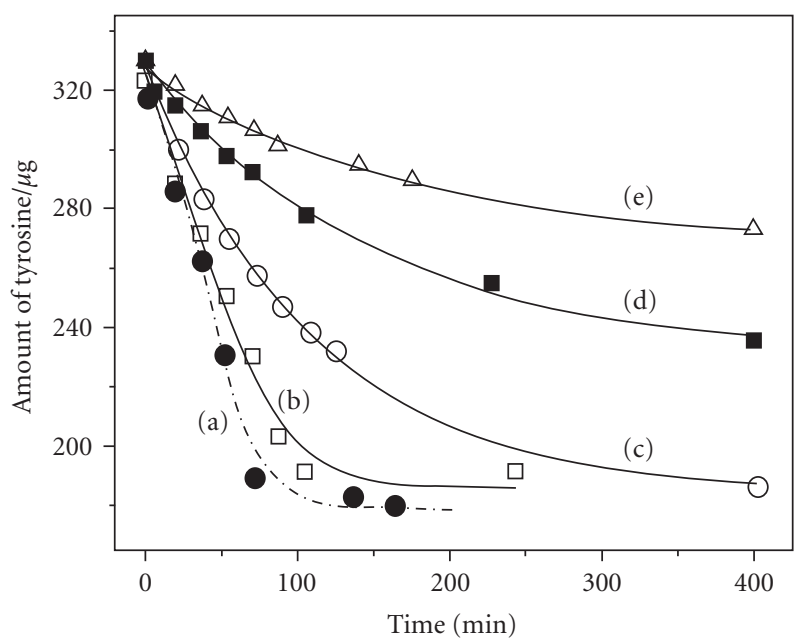

FIGURE 4: Inhibition of the LPO-catalyzed iodination of L-tyrosine by MSeI. The decrease in the amount of tyrosine with time was followed by HPLC: (a) control; (b) $6 \mu \mathrm{M}$ of 2 ; (c) $9 \mu \mathrm{M}$ of 2 ; (d) $12 \mu \mathrm{M}$ of 2 ; (d) $15 \mu \mathrm{M}$ of 2 ; and (e) $20 \mu \mathrm{M}$ of 2 (see [49]).

obtained by injecting known concentrations of L-tyrosine. The effect of compound 2 on the iodination reaction was determined at various concentrations of 2 under identical experimental conditions (Figure 4). The incubation mixtures for the HPLC analysis contained KI, L-tyrosine, hydrogen peroxide, and LPO enzyme. The mixture was incubated in phosphate buffer at room temperature and aliquots were injected onto the HPLC column and eluted with gradient solvent system $(0.1 \%$ TFA in water-MeCN). The decrease in the amount of tyrosine $(\mu \mathrm{g})$ was calculated from the calibration plot. The concentration of compound 2 was varied from $6 \mu \mathrm{M}$ to $20 \mu \mathrm{M}$, and a significant inhibition was observed even at the lowest concentration of 2 .

To understand the effect of peroxide substrate on the reaction rate and the inhibition, the LPO activity was determined at various concentrations of hydrogen peroxide. In addition, the effect of peroxide on the inhibition of LPOcatalyzed iodination by antithyroid drugs 1 and 2 was evaluated by carrying out the experiments at various concentrations of $\mathrm{H}_{2} \mathrm{O}_{2}$. In this HPLC assay, the incubation mixtures containing KI, L-tyrosine, LPO enzyme, and various concentrations of hydrogen peroxide were incubated at room temperature. The aliquots were removed from the reaction mixture at various time intervals, injected onto the HPLC column and eluted with gradient solvent system $(0.1 \%$ TFA in water-MeCN). The formation of monoiodo tyrosine was followed at $295 \mathrm{~nm}$. The initial rates $\left(\mathrm{v}_{0}\right)$ derived for various concentrations of $\mathrm{H}_{2} \mathrm{O}_{2}$ were plotted against the concentration of $\mathrm{H}_{2} \mathrm{O}_{2}$. Although the LPO activity was inhibited by 2 at lower concentrations of $\mathrm{H}_{2} \mathrm{O}_{2}$, the enzyme's activity could be completely recovered by increasing $\mathrm{H}_{2} \mathrm{O}_{2}$ concentration (Figure 5). These results suggest that the concentration of $\mathrm{H}_{2} \mathrm{O}_{2}$ has a dramatic effect on the inhibition of iodination reaction by compound 2 (Figure 5) [49]. 


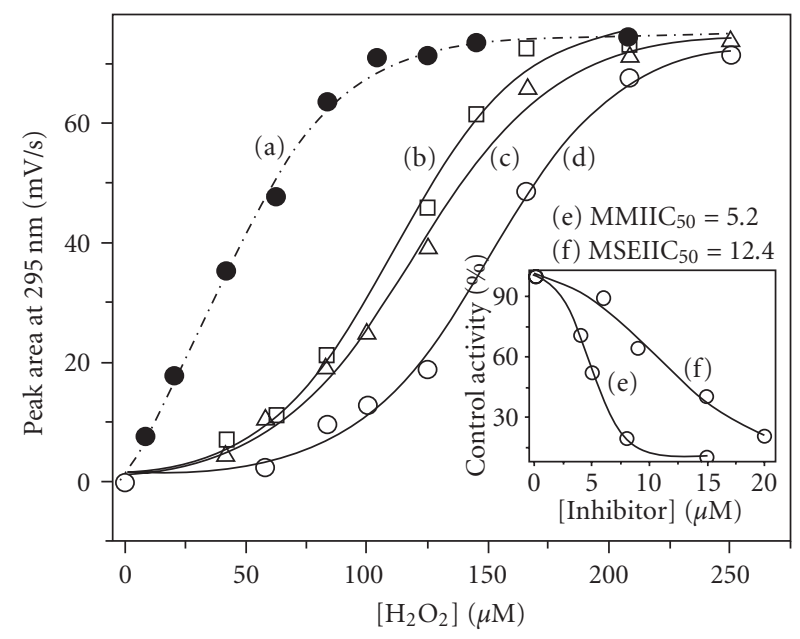

FIGURE 5: Inhibition of the LPO-catalyzed iodination of L-tyrosine by MSeI. Effect of $\mathrm{H}_{2} \mathrm{O}_{2}$ on the inhibition by 2; (a) $0 \mu \mathrm{M}$; (b) $20 \mu \mathrm{M}$; (c) $30 \mu \mathrm{M}$; (d) $40 \mu \mathrm{M}$; inset: inhibition of tyrosine iodination by (e) 1; (f) 2 at a fixed $\mathrm{H}_{2} \mathrm{O}_{2}$ concentration.

The $\mathrm{IC}_{50}$ values for the inhibition of LPO-catalyzed iodination of L-tyrosine by the test compounds were also determined by following the same procedure. The initial rates for the iodination reaction were determined at various concentrations of inhibitors. The inhibition curves obtained by plotting the percentage control activity against the concentration of inhibitors are shown in Figure 5 (inset). As expected, MMI exhibited a strong inhibition with an $\mathrm{IC}_{50}$ value of $5.2 \mu \mathrm{M}$, which is comparable with the $\mathrm{IC}_{50}$ value obtained for the LPO-catalyzed oxidation reaction [30, 31]. The selenium analogue (2) also showed a strong inhibition with an IC $_{50}$ value of $12.4 \mu \mathrm{M}$, which is consistent with the effect of this compound on peroxidase-catalyzed oxidation reactions $[30,31]$. Similarly to the LPO-catalyzed oxidation of $2,2^{\prime}$ azino-bis-3-ethylbenz-thiazoline sulfonic acid (ABTS), this suggests that the selenium analogue may inhibit the LPO by a different mechanism. The diselenide 8 , on the other hand, did not show any noticeable inhibition under identical conditions. This confirms that the reduction of the diselenide to the corresponding selenolate is essential for an efficient inhibition of LPO-catalyzed oxidation or iodination reactions.

\section{INTERACTION OF ANTITHYROID DRUGS WITH IODINE}

The nature of charge-transfer complexes between heterocyclic antithyroid drugs and diiodine is an important area of interest in the study of hyperthyroidism [50], and the electrical properties in general and the superconducting ability, in particular, of sulfur-iodine complexes are also of current interest [51-54]. Recently, a great deal of effort has been devoted to the understanding of the interaction of antithyroid drugs with iodine [55-59]. These studies may provide insight into the nature of products formed during the inhibition of thyroid hormone synthesis. As mentioned in the introduction, it has been proposed that these drugs may divert
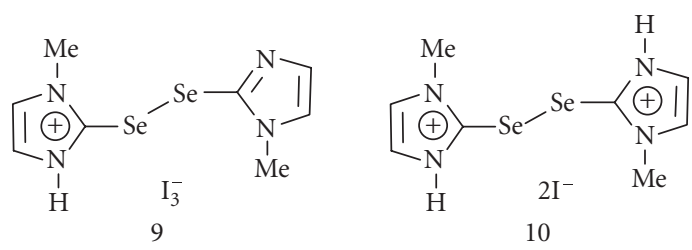

Figure 6: Chemical structures of compounds 9 and 10 derived from the compound 2 .

oxidized iodides away from thyroglobulin by forming stable electron donor-acceptor complexes with diiodine, which can effectively reduce the thyroid hormone biosynthesis $[19,20]$. Because the oxidation of MMI to the corresponding disulfide (7) by $\mathrm{TPO} / \mathrm{H}_{2} \mathrm{O}_{2} / \mathrm{I}^{-}$system is associated with the reaction of MMI with $\mathrm{I}_{2}$ [55-59], we have investigated the interaction of 2 and 8 with iodine. It has been reported that $I_{2}$ chemically oxidizes MMI to produce ionic disulfides that exist in two different protonated forms [55]. It is unknown whether the selenium analogue of MMI, in its reduced form, also undergoes such oxidation by $\mathrm{I}_{2}$ to produce ionic species (Figure 6). Therefore, we carried out the experiments with the reduced species (2), which exists in its zwitterionic form $[31,35]$. The reaction of 2 with $\mathrm{I}_{2}$ in $\mathrm{CH}_{2} \mathrm{Cl}_{2}$ produced red-brown crystals. Interestingly, the X-ray crystal structure shows the formation of compound 9, which consists of a monocation containing a diselenide and $\mathrm{I}_{3}{ }^{-}$as counterion (Figure 7) [49]. This is in contrast to the reaction of MMI with $\mathrm{I}_{2}$ in $\mathrm{CH}_{2} \mathrm{Cl}_{2}$, which afforded a disulfide-containing dication and $\mathrm{I}_{8}{ }^{-}$as counterions [55].

The formation of the monocationic species 9 is interesting from a chemical point of view as only one of the imidazole rings undergoes oxidation. It should be mentioned that the N-methylation on MMI has been shown to abolish its TPO inhibitory activity [60]. Freeman et al have shown that the reaction of the $\mathrm{N}$-methylated derivative (1,3-dimethylimidazole-2-thione) with $\mathrm{I}_{2}$ does not produce any disulfide, but it produces a $1: 1$ thione : $\mathrm{I}_{2}$ chargetransfer adduct [61]. The N-methylated derivative of 2 (1,3dimethylimidazole-2-selone), on the other hand, produces a hypervalent "T-shaped" compound having I-Se-I moiety $[62,63]$. It should be noted that the reaction of the methylated analogue of 2, 1,3-dimethylimidazole-2-selone, with one equivalent bromine affords a hypervalent compound having $\mathrm{Br}-\mathrm{Se}-\mathrm{Br}$ moiety, whereas the corresponding reaction utilizing a half-equivalent bromine leads to the formation of a diselenide dication having two $\mathrm{Br}^{-}$as counterions [64]. Therefore, the existence of 2 in its zwitterionic (or selenolate) form is probably responsible for its different reactivity toward iodine. Stable open-chain cationic diselenide species are very uncommon in the literature and to the best of our knowledge no structural information is available for complexes derived from the reactions of selenium analogues of antithyroid drugs with iodine. The chemical oxidation of 2 by $\mathrm{I}_{2}$ suggests that compound 8 , which exists in the oxidized form of 2, may not produce any ionic species. To test this, the diselenide 8 was treated with $\mathrm{I}_{2}$ in a $1: 2$ molar ratio in $\mathrm{CH}_{2} \mathrm{Cl}_{2}$. 


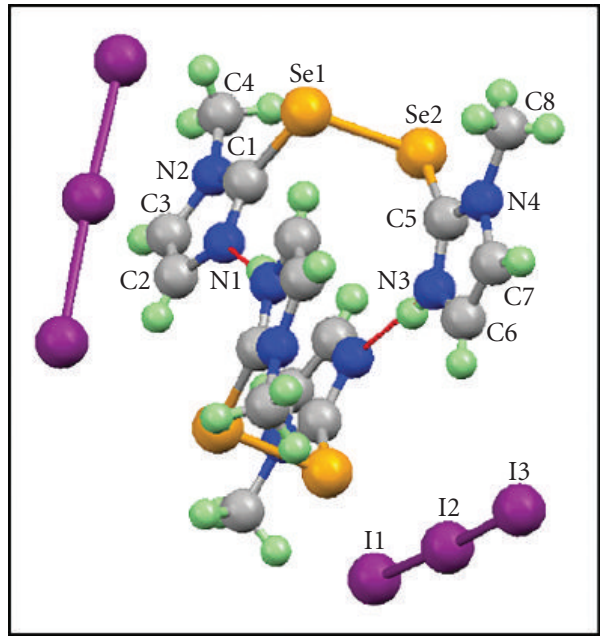

(a)

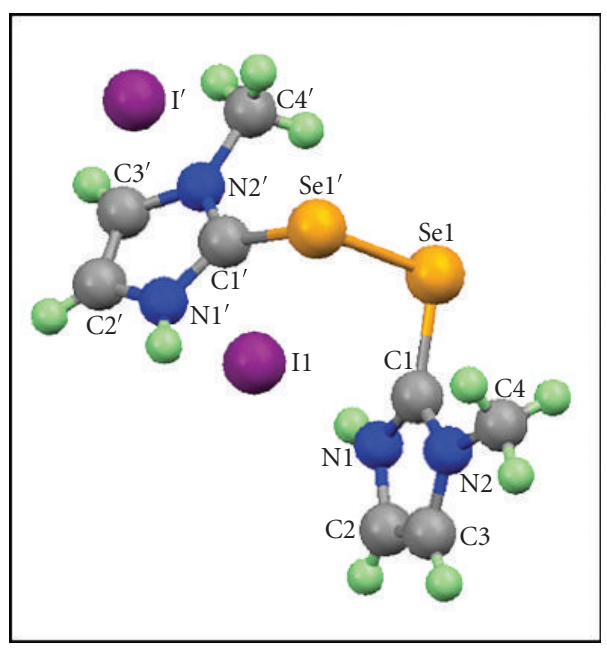

(b)

FIgURE 7: Molecular structures of (a) monocation 9 showing the hydrogen bonding between two monocations and (b) dication 10 [49].

This reaction yielded a brown solution from which darkbrown crystals were obtained on standing at room temperature. Surprisingly, the X-ray crystal structure shows the formation of a monocationic species, which is identical with that obtained from the reaction of 2 with $\mathrm{I}_{2}$ (Figure 7). The formation of a cationic species in this reaction is quite unexpected because the reactions of iodine with diselenides generally produce selenenyl iodide species or charge-transfer complexes having diselenide-molecular iodine adducts [65]. It is also known that some of the selenenyl iodides may undergo disproportionation to give diselenide-iodine complexes.

The far-IR spectrum of complex 9 shows a distinct band at $135 \mathrm{~cm}^{-1}$ for the $v(\mathrm{I}-\mathrm{I})$ stretching vibration mode. This

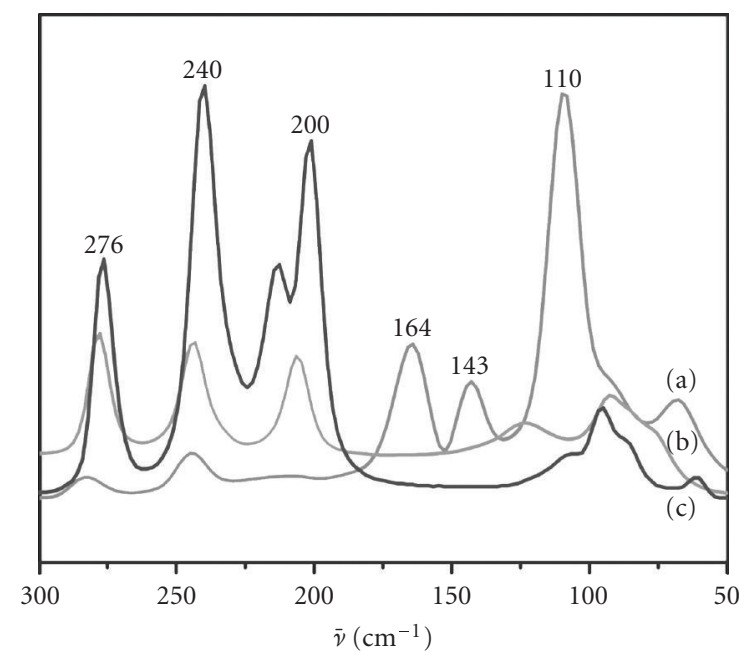

Figure 8: FT-Raman spectra of the monocation 9 (a), diselenide 8 (b), and the dication 10 (c) (see [49]).

is in agreement with the fact that $I_{2}$ gives a strong band at $180 \mathrm{~cm}^{-1}$ in the solid state, which shifts to lower wavenumbers upon coordination to a donor atom, reflecting a reduction in the I-I bond order [56]. The FT-Raman spectrum of the complex in the $v(\mathrm{I}-\mathrm{I})$ region shows intense peaks at $164 \mathrm{~cm}^{-1}, 143 \mathrm{~cm}^{-1}$, and $110 \mathrm{~cm}^{-1}$. In addition, a weak band is observed around $67 \mathrm{~cm}^{-1}$ (Figure 8). The band at $110 \mathrm{~cm}^{-1}$ can be certainly assigned to the $\nu_{1}$ symmetric stretching of $\mathrm{I}_{3}{ }^{-}$, which being a symmetrical ion normally exhibits only one Raman active band. However, when a distortion of $\mathrm{I}_{3}{ }^{-}$occurs, the antisymmetric stretching may become Raman active and additional bands at higher $\left(140 \mathrm{~cm}^{-1}\right.$ $\left.130 \mathrm{~cm}^{-1}\right)$ and at lower frequencies $\left(80 \mathrm{~cm}^{-1}-70 \mathrm{~cm}^{-1}\right)$ may be observed $[56,66]$. Therefore, the relatively weak bands at $143 \mathrm{~cm}^{-1}$ and $67 \mathrm{~cm}^{-1}$ can be attributed to the antisymmetric stretching and deformation motions, respectively, for the $\mathrm{I}_{3}{ }^{-}$ion (Figure 8a).

The single crystal X-ray studies confirm the proposed structure of 9 (Figure 7), which consists of two independent diselenide monocations [Se-Se: $2.382 \AA ; 2.364 \AA$ ]. These diselenide cations interact with their symmetry equivalents through $\mathrm{N}-\mathrm{H} \cdots \mathrm{N}$ hydrogen bonds to form dimeric units with overall charge $2+$. The charge balance in the crystals is achieved by the presence of two $\mathrm{I}_{3}{ }^{-}$anions. The two $\mathrm{C}-\mathrm{Se}$ bond lengths in each subunit are unequal due to the monoprotonation of the one of the five-membered rings [C-Se: 1.886-1.890 ̊]. The I-I bond lengths observed also differ significantly from the corresponding I-I bond length of $\mathrm{I}_{2}$ in the solid state $(2.715 \AA)$. The two I-I bond lengths of the $\mathrm{I}_{3}{ }^{-}$species in complex 9 range from $2.888 \AA$ to $2.919 \AA$, indicating a slight distortion of the $\mathrm{I}_{3}{ }^{-}$moiety. This distortion is probably responsible for additional bands in the FT-Raman spectrum of the complex.

In the reaction between 8 and $\mathrm{I}_{2}$ in dichloromethane, the concentrations of $I_{2}$ do not appear to change the nature of products. During our attempts to oxidize the second 
ring using various concentrations of $\mathrm{I}_{2}$ up to an excess, only the monocation was obtained as a stable product. However, the choice of solvent has been found to have a large influence on the nature of products formed. The reaction of 8 with $\mathrm{I}_{2}$ in a $1: 2$ molar ratio in water produced a mixture containing both monocation (9) and dication (10) as confirmed by single-crystal X-ray studies (Figure 7). In contrast to the monocation, the charge balance in the crystal of dication is achieved by two $\mathrm{I}^{-}$anions. In compound 10, the average $\mathrm{C}$-Se bond length of $1.895 \AA$ is comparable with that of the diselenide 8 (1.880 $\AA$ ) [30], but this is significantly longer than the average C-Se bond length (1.848 $\AA$ ) found in compound 2 that exists in a zwitterionic form [35]. As expected, the FT-Raman spectrum of compound 10 shows no peaks in the region of lower wavenumbers (Figure 8c), indicating the absence of any polyiodide species in the crystals.

\section{CONCLUSION AND OUTLOOK}

Our recent results show that the selenium analogue of methimazole (MSeI) exists predominantly in its zwitterionic form, in which the selenium atom carries a negative charge and the five-membered heterocyclic ring carries a positive charge. In contrast to the sulfur analogue, the zwitterionic form of MSeI is unstable and oxidizes in air to the corresponding diselenide. The resulting diselenide can be easily reduced by reducing agents such as $\mathrm{NaBH}_{4}$ or glutathione (GSH). In its reduced form (zwitterionic or selenolate), MSeI effectively and reversibly inhibits the lactoperoxidase (LPO)-catalyzed oxidation reactions. These results suggest that MSeI may not interfere with the native enzyme directly, but it may inhibit LPO either by reducing the $\mathrm{H}_{2} \mathrm{O}_{2}$ that is required for the oxidation of the iron center in LPO or by interfering with the oxidized enzyme. In the presence of GSH, MSeI may constitute a redox cycle involving a catalytic reduction of $\mathrm{H}_{2} \mathrm{O}_{2}$ and thereby mimics the glutathione peroxidase (GPx) activity in vitro. In addition, MSeI effectively inhibits the LPOcatalyzed iodination of L-tyrosine and the inhibition could be completely recovered by increasing the $\mathrm{H}_{2} \mathrm{O}_{2}$ concentration. These studies reveal that the degradation of the intracellular $\mathrm{H}_{2} \mathrm{O}_{2}$ by the selenium analogues of antithyroid drugs may be beneficial to the thyroid gland as these compounds may act as antioxidants and protect thyroid cells from oxidative damage. In addition to its antioxidant activity, MSeI reacts with $\mathrm{I}_{2}$ to produce novel ionic diselenides containing iodide or polyiodide anions, which might be effective intermediates in the inhibition of thyroid hormones. However, further studies with TPO are required to derive some firm conclusions regarding the mode of action of the antithyroid drugs. Our future work will focus on the design and synthesis of novel sulfur and selenium compounds and study of their antithyroid and antioxidant activities.

\section{ACKNOWLEDGMENT}

This study was supported by the Department of Science and Technology (DST), New Delhi, India.

\section{REFERENCES}

[1] Taurog A. Hormone synthesis: thyroid iodine. In: Braverman LE, Utiger RD, eds. Werner and Ingbar's the Thyroid. Philadelphia, Pa: Lippincott Williams \& Wilkins; 1991:51-97.

[2] Taurog A, Dorris M, Doerge DR. Evidence for a radical mechanism in peroxidase-catalyzed coupling. 1. Steady-state experiments with various peroxidases. Archives of Biochemistry and Biophysics. 1994;315(1):82-89.

[3] Doerge DR, Taurog A, Dorris ML. Evidence for a radical mechanism in peroxidase-catalyzed coupling. II. Single turnover experiments with horseradish peroxidase. Archives of Biochemistry and Biophysics. 1994;315(1):90-99.

[4] Doerge DR, Divi RL. Porphyrin $\pi$-cation and protein radicals in peroxidase catalysis and inhibition by anti-thyroid chemicals. Xenobiotica. 1995;25(7):761-767.

[5] Taurog A, Dorris ML, Doerge DR. Mechanism of simultaneous iodination and coupling catalyzed by thyroid peroxidase. Archives of Biochemistry and Biophysics. 1996;330(1):24-32.

[6] Behne D, Kyriakopoulos A, Meinhold H, Köhrle J. Identification of type I iodothyronine $5^{\prime}$-deiodinase as a selenoenzyme. Biochemical and Biophysical Research Communications. 1990;173(3):1143-1149.

[7] Berry MJ, Banu L, Larsen PR. Type I iodothyronine deiodinase is a selenocysteine-containing enzyme. Nature. 1991;349(6308):438-440.

[8] Berry MJ, Kieffer JD, Harney JW, Larsen PR. Selenocysteine confers the biochemical properties characteristic of the type I iodothyronine deiodinase. Journal of Biological Chemistry. 1991;266(22):14155-14158.

[9] Köhrle J. Thyroid hormone deiodination in target tissues-a regulatory role for the trace element selenium? Experimental and Clinical Endocrinology. 1994;102(2):63-89.

[10] Larsen PR, Berry MJ. Nutritional and hormonal regulation of thyroid hormone deiodinases. Annual Review of Nutrition. 1995; 15:323-352.

[11] St. Germain DL, Galton VA. The deiodinase family of selenoproteins. Thyroid. 1997;7(4):655-668.

[12] Köhrle J. The trace element selenium and the thyroid gland. Biochimie. 1999;81(5):527-533.

[13] Bianco AC, Salvatore D, Gereben B, Berry MJ, Larsen PR. Biochemistry, cellular and molecular biology, and physiological roles of the iodothyronine selenodeiodinases. Endocrine Reviews. 2002;23(1):38-89.

[14] Köhrle J. Iodothyronine deiodinases. Methods in Enzymology. 2002;347:125-167.

[15] Köhrle J. Selenium and the control of thyroid hormone metabolism. Thyroid. 2005;15(8):841-853.

[16] Köhrle J, Jakob F, Contempré B, Dumont JE. Selenium, the thyroid, and the endocrine system. Endocrine Reviews. 2005;26(7):944-984.

[17] Leonard JL, Visser TJ. Biochemistry of deiodination. In: Hennemann G, ed. Thyroid Hormone Metabolism. New York, NY: Marcel Dekker; 1986:189-229.

[18] Goswami A, Rosenberg IN. Stimulation of iodothyronine outer ring monodeiodinase by dihydrolipoamide. Endocrinology. 1983;112(4):1180-1187.

[19] Buxeraud J, Absil A-C, Claude J, Raby C, Catanzano G, Beck C. Antithyroid agents: structure-activity relationship. II. Interpretation of mechanism of action by complexation of charge transfer. European Journal of Medicinal Chemistry. 1985;20(1):43-50. 
[20] Raby C, Lagorce J-F, Jambut-Absil A-C, Buxeraud J, Catanzano G. The mechanism of action of synthetic antithyroid drugs: iodine complexation during oxidation of iodide. Endocrinology. 1990;126(3):1683-1691.

[21] Basosi R, Niccolai N, Rossi C. Coordination behaviour of antithyroid drugs against the $\mathrm{Fe}(\mathrm{I})(\mathrm{NO})_{2}$ group in solution: ESR and FT-NMR study. Biophysical Chemistry. 1978;8(1):61-69.

[22] du Mont W-W, Mugesh G, Wismach C, Jones PG. Reactions of organoselenenyl iodides with thiouracil drugs: an enzyme mimetic study on the inhibition of iodothyronine deiodinase. Angewandte Chemie. International Edition. 2001;40(13):24862489.

[23] Roy G, Mugesh G. Chemistry in thyroid gland: iodothyronine deiodinases and anti-thyroid drugs. Phosphorus, Sulfur and Silicon and the Related Elements. 2005;180(3-4):891-902.

[24] Roy G, Sarma BK, Phadnis PP, Mugesh G. Seleniumcontaining enzymes in mammals: chemical perspectives. Journal of Chemical Sciences. 2005;117(4):287-303.

[25] Visser TJ, Kaptein E, Aboul-Enein HY. Selenouracil derivatives are potent inhibitors of the selenoenzyme type I iodothyronine deiodinase. Biochemical and Biophysical Research Communications. 1992;189(3):1362-1367.

[26] Aboul-Enein HY, Awad AA, Al-Andis NM. Synthesis and the antiperoxidase activity of seleno analogues of the antithyroid drug propylthiouracil. Journal of Enzyme Inhibition. 1993;7(2):147-150.

[27] Taurog A, Dorris ML, Guziec LJ, Guziec FS Jr. The selenium analog of methimazole. Measurement of its inhibitory effect on type I $5^{\prime}$-deiodinase and of its antithyroid activity. Biochemical Pharmacology. 1994;48(7):1447-1453.

[28] Guziec LJ, Guziec FS Jr. A directed metalation route to the selenium analog of methimazole. Journal of Organic Chemistry. 1994;59(16):4691-4692.

[29] Taurog A, Dorris ML, Hu W-X, Guziec FS Jr. The selenium analog of 6-propylthiouracil. Measurement of its inhibitory effect on type I iodothyronine deiodinase and of its antithyroid activity. Biochemical Pharmacology. 1995;49(5):701-709.

[30] Roy G, Nethaji M, Mugesh G. Biomimetic studies on antithyroid drugs and thyroid hormone synthesis. Journal of the American Chemical Society. 2004;126(9):2712-2713.

[31] Roy G, Mugesh G. Anti-thyroid drugs and thyroid hormone synthesis: effect of methimazole derivatives on peroxidasecatalyzed reactions. Journal of the American Chemical Society. 2005;127(43):15207-15217.

[32] Taurog A, Dorris ML, Lamas L. Comparison of lactoperoxidase- and thyroid peroxidase-catalyzed iodination and coupling. Endocrinology. 1974;94(5):1286-1294.

[33] Childs RE, Bardsley WG. The steady-state kinetics of peroxidase with 2, 2' -azino-di-(3-ethyl-benzthiazoline-6-sulphonic acid) as chromogen. The Biochemical Journal. 1975;145(1):93103.

[34] Laurence C, El Ghomari MJ, Le Questel J-Y, Berthelot M, Mokhlisse R. Structure and molecular interactions of antithyroid drugs. Part 3. Methimazole: a diiodine sponge. Journal of the Chemical Society, Perkin Transactions 2. 1998;(7):15451552.

[35] Roy G, Das D, Mugesh G. Bioinorganic chemistry aspects of the inhibition of thyroid hormone biosynthesis by anti-hyperthyroid drugs. Inorganica Chimica Acta. In press. http://dx.doi.org/10.1016/j.ica.2006.07.052.

[36] Engler H, Taurog A, Luthy C, Dorris ML. Reversible and irreversible inhibition of thyroid peroxidase-catalyzed iodination by thioureylene drugs. Endocrinology. 1983;112(1):86-95.
[37] Taurog A. The mechanism of action of the thioureylene antithyroid drugs. Endocrinology. 1976;98(4):1031-1046.

[38] Nogimori T, Braverman LE, Taurog A, Fang S-L, Wright G, Emerson $\mathrm{CH}$. A new class of propylthiouracil analogs: comparison of $5^{\prime}$-deiodinase inhibition and antithyroid activity. Endocrinology. 1986;118(4):1598-1605.

[39] Taurog A, Dorris ML, Guziec FS Jr. Metabolism of ${ }^{35}$ S- and ${ }^{14} \mathrm{C}$-labeled 1-methyl-2-mercaptoimidazole in vitro and in vivo. Endocrinology. 1989;124(1):30-39.

[40] Doerge DR. Oxygenation of organosulfur compounds by peroxidases: evidence of an electron transfer mechanism for lactoperoxidase. Archives of Biochemistry and Biophysics. 1986;244(2):678-685.

[41] Kobayashi S, Nakano M, Goto T, Kimura T, Schaap AP. An evidence of the peroxidase-dependent oxygen transfer from hydrogen peroxide to sulfides. Biochemical and Biophysical Research Communications. 1986;135(1):166-171.

[42] Doerge DR. Mechanism-based inhibition of lactoperoxidase by thiocarbamide goitrogens. Biochemistry. 1986;25(16): 4724-4728.

[43] Doerge DR, Pitz GL, Root DP. Organosulfur oxygenation and suicide inactivation of lactoperoxidase. Biochemical Pharmacology. 1987;36(6):972-974.

[44] Doerge DR, Takazawa RS. Mechanism of thyroid peroxidase inhibition by ethylenethiourea. Chemical Research in Toxicology. 1990;3(2):98-101.

[45] Doerge DR, Cooray NM, Brewster ME. Peroxidase-catalyzed S-oxygenation: mechanism of oxygen transfer for lactoperoxidase. Biochemistry. 1991;30(37):8960-8964.

[46] Mugesh G, du Mont W-W, Sies H. Chemistry of biologically important synthetic organoselenium compounds. Chemical Reviews. 2001;101(7):2125-2179.

[47] Björkman U, Ekholm R. Hydrogen peroxide degradation and glutathione peroxidase activity in cultures of thyroid cells. Molecular and Cellular Endocrinology. 1995;111(1):99-107.

[48] Ekholm R, Björkman U. Glutathione peroxidase degrades intracellular hydrogen peroxide and thereby inhibits intracellular protein iodination in thyroid epithelium. Endocrinology. 1997;138(7):2871-2878.

[49] Roy G, Nethaji M, Mugesh G. Interaction of anti-thyroid drugs with iodine: the isolation of two unusual ionic compounds derived from Se-methimazole. Organic and Biomolecular Chemistry. 2006;4(15):2883-2887.

[50] Cooper DS. Antithyroid drugs. The New England Journal of Medicine. 2005;352(9):905-917.

[51] Inabe T, Matsunago Y. Physical properties and constitution of the 5,6:11,12- bis(epidithio)naphthacene-iodine complexes $\left(\mathrm{TTT}-\mathrm{I}_{n}\right)$. Bulletin of the Chemical Society of Japan. 1978;51(10):2813-2816.

[52] Matsunago Y, Suzuki Y. Electrical and optical properties of the iodine complexes of phenoxazine, phenoselenazine, and benzophenothiazines. Bulletin of the Chemical Society of Japan. 1972;45(11):3375-3379.

[53] Sano M, Ohno K, Akamatu H. Thermoelectric power of the iodine complexes of aromatic diamines and thiazines. Bulletin of the Chemical Society of Japan. 1971;44(12):3269-3271.

[54] Murata K, Tokumoto M, Anjai H, et al. Superconductivity with the onset at $8-\mathrm{K}$ in the organic conductor beta-(BEDTTTF $)_{2} \mathrm{I}_{3}$ under pressure. Journal of the Physical Society of Japan. 1985;54(4):1236-1239.

[55] Aragoni MC, Arca M, Demartin F, et al. Anti-thyroid drug methimazole: X-ray characterization of two novel ionic disulfides obtained from its chemical oxidation by $\mathrm{I}_{2}$. Journal of the American Chemical Society. 2002;124(17):4538-4539. 
[56] Antoniadis CD, Corban GJ, Hadjikakou SK, et al. Synthesis and characterization of $(\mathrm{PTU}) \mathrm{I}_{2}$ (PTU $=6-n$-propyl-2thiouracil) and (CMBZT) $\mathrm{I}_{2}$ (CMBZT $=5$-chloro-2-mercaptobenzothiazole) and possible implications for the mechanism of action of anti-thyroid drugs. European Journal of Inorganic Chemistry. 2003;2003(8):1635-1640.

[57] Aragoni MC, Arca M, Demartin F, et al. DFT calculations, structural and spectroscopic studies on the products formed between IBr and $N, N^{\prime}$-dimethylbenzoiimdazole2(3H)-thione and $-2(3 H)$-selone. Dalton Transactions. 2005;(13):2252-2258.

[58] Corban GJ, Hadjikakou SK, Hadjiliadis N, et al. Synthesis, structural characterization, and computational studies of novel diiodine adducts with the heterocyclic thioamides $N$ methylbenzothiazole-2-thione and benzimidazole-2-thione: implications with the mechanism of action of antithyroid drugs. Inorganic Chemistry. 2005;44(23):8617-8627.

[59] Antoniadis CD, Hadjikakou SK, Hadjiliadis N, Papakyriakou A, Baril M, Butler IS. Synthesis and structures of Se analogues of the antithyroid drug 6-n-propyl-2-thiouracil and its alkyl derivatives: formation of dimeric Se-Se compounds and deselenation reactions of charge-transfer adducts of diiodine. Chemistry - A European Journal. 2006;12(26):6888-6897.

[60] Visser TJ, van Overmeeren E, Fekkes D, Docter R, Hennemann G. Inhibition of iodothyronine 5 -deiodinase by thioureylenes; structure-activity relationship. FEBS Letters. 1979;103(2):314-318.

[61] Freeman F, Ziller JW, Po HN, Keindl MC. Reactions of imidazole-2-thiones with molecular iodine and the structures of two crystalline modifications of the 1:1 1,3dimethylimidazole-2-thione-diiodine charge-transfer complex $\left(\mathrm{C}_{5} \mathrm{H}_{8} \mathrm{I}_{2} \mathrm{~N}_{2} \mathrm{~S}\right)$. Journal of the American Chemical Society. 1988;110(8):2586-2591.

[62] Bigoli F, Deplano P, Devillanova FA, et al. Reaction of imidazole-2-selone derivatives with diiodine-synthesis, structural and spectroscopic characterization of the adduct $1,1^{\prime}$ bis(3-methyl-4-imidazolin-2-selone)methane bis(diiodine) and of the 1st examples of I-Se-I hypervalent seleniumcompounds- 1,3-dimethyl-4-imidazolin-2-ylium diiodo selenanide and 1,2-bis(3-methyl- 4-imidazolin-2-ylium diiodo selenanide)-ethane bis(dichloromethane). Gazzetta Chimica Italiana. 1994;124(11):445-454.

[63] Aragoni MC, Arca M, Blake AJ, et al. 1,2-Bis(3-methylimidazolin-2-ylium iodobromoselenanide)ethane: oxidative addition of $\mathrm{IBr}$ at the Se atom of a $>\mathrm{C}=$ Se Group. Angewandte Chemie International Edition. 2001;40(22):4229-4232.

[64] Williams DJ, Fawcett-Brown MR, Raye RR, et al. Synthesis, characterization, and X-ray crystallographic structure of 1,3- dimeihyl-2 (3H)-imidazoleselone. Heteroatom Chemistry. 1993;4(4):409-414.

[65] du Mont W-W, Martens von Salzen A, Ruthe F, et al. Tunning selenium-iodine contacts: from secondary soft-soft interactions to covalent bonds. Journal of Organometallic Chemistry. 2001;623(1-2):14-28.

[66] Deplano P, Ferraro JR, Mercuri ML, Trogu EF. Structural and Raman spectroscopic studies as complementary tools in elucidating the nature of the bonding in polyiodides and in donor$\mathrm{I}_{2}$ adducts. Coordination Chemistry Reviews. 1999;188(1):7195. 


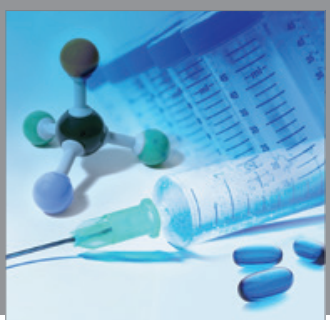

International Journal of

Medicinal Chemistry

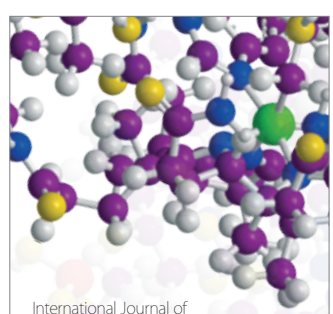

Carbohydrate Chemistry

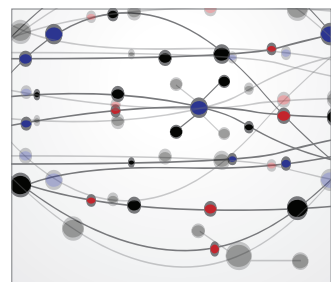

The Scientific World Journal
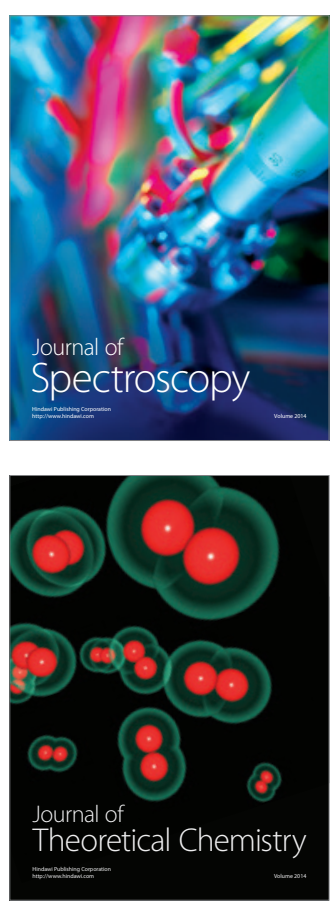
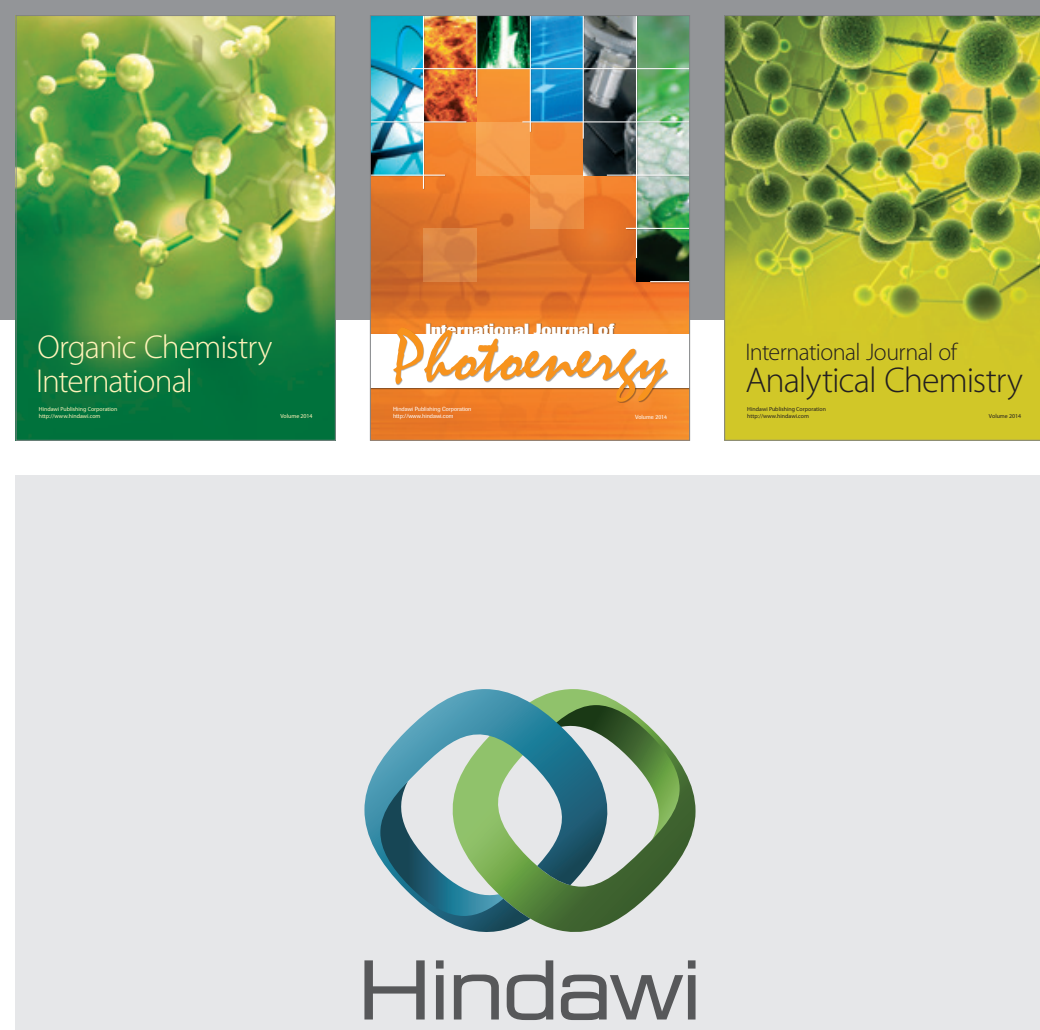

Submit your manuscripts at

http://www.hindawi.com
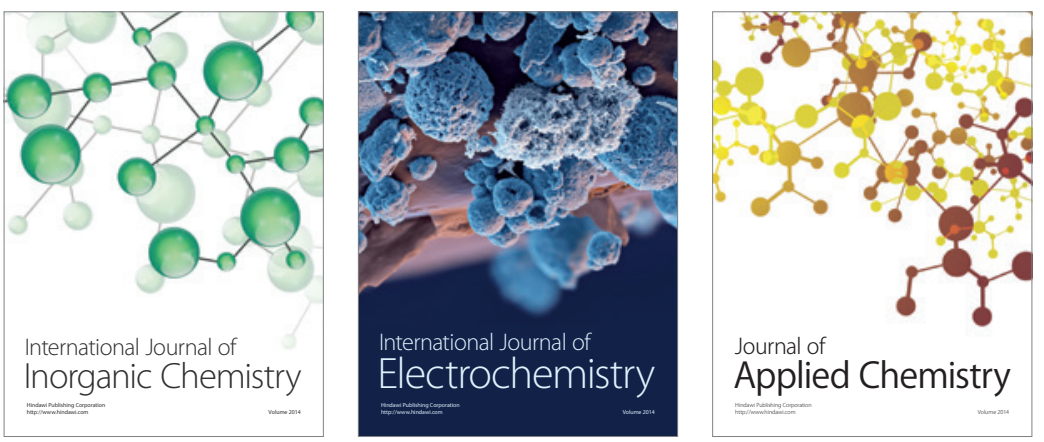

Journal of

Applied Chemistry
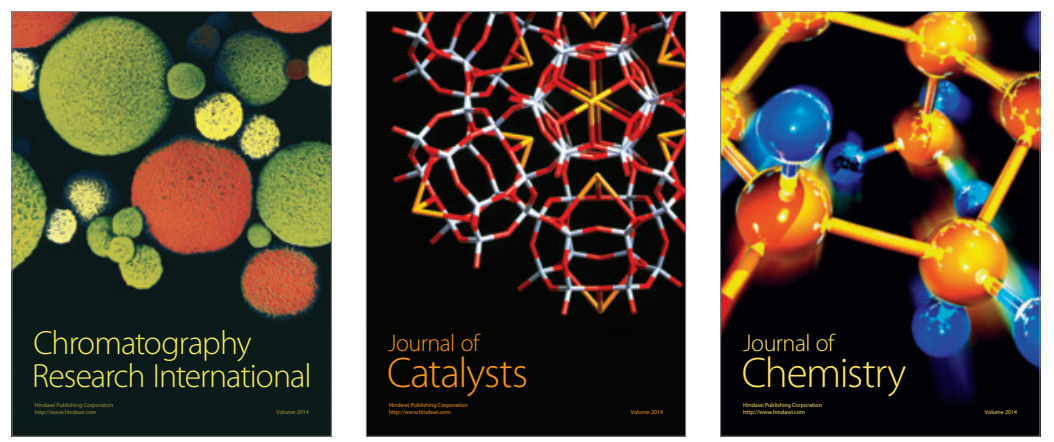
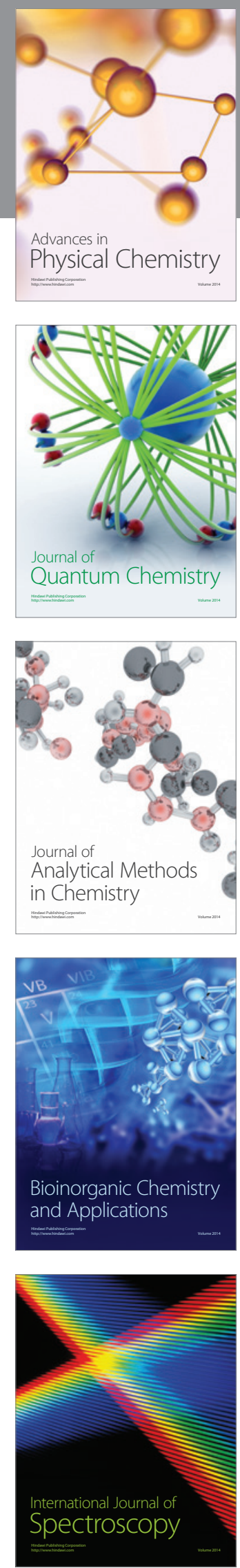